\title{
The Effectiveness of Teaching an Educational Unit According to the Learning Cycle-5 Es Model "Bybee" in the Development of Problem-Solving Skills and Academic Achievement in Geography Subject in Grade 9 in Jordan
}

\author{
Jamal Abdel Fattah Al Assaf ${ }^{1, *}$ \\ ${ }^{1}$ Department of Educational Sciences, Balqa Applied University, Jordan \\ *Correspondence: Department of Educational Sciences, Balqa Applied University, Jordan. E-mail: \\ Dr.Jamal.assaf@bau.edu.jo
}

Received: July 15, 2019 Accepted: August 21, 2019 Online Published: August 25, 2019

doi:10.5430/jct.v8n3p143 URL: https://doi.org/10.5430/jct.v8n3p143

\begin{abstract}
The aim of this study is to investigate the effectiveness of the learning cycle-5 Es model "Bybee "in the development of problem-solving skills and academic achievement in Geography subject in the ninth graders in Jordan. The study consists of 60 students from the University Education Directorate in Amman in the second semester for the year 2017/ 2018. The sample was distributed randomly into two groups; one of which is experimental of (30 students) and was taught according to the Bybee model. The other was a control group, which consisted of (30) students and was taught in the usual way. The study tools consisted of the cognitive achievement test and the capacity scale for problem-solving.

The results of the study showed that there were statistically significant differences in the average achievement of the ninth-grade students in geography subject, due to the impact of the teaching strategy in favor of the experimental group. Also, it showed statistically significant differences in the average achievement of ninth grade students in geography, due to the teaching strategy of problem-solving skills and in favor of the experimental group.

The researcher recommended the benefit of the learning model "Bybee" in teaching the geography subject at all stages of the upper stage.
\end{abstract}

Keywords: learning model "Bybee", problem-solving, academic achievement, geography

\section{Introduction}

The educational systems in Jordan seek to provide an educational environment for thinking. At the top of these systems is the guidelines of Ministry of Education in Jordan; based on improving the personality of the learner to have motivation and flexibility in thinking and in dealing with others. In addition to the ability to cooperate Negotiation with them, as well as the ability to recognize the relationships between the new information that the learner generates and his previous information (MOE, 2013, p.170-193).

This pose a challenge to educational policy makers in seeking to address the need for new theories, strategies and models that contribute to the growth of learners' mentality and develop their science processes and to be able to solve problems in life situations. Furthermore, to learn how to live them and apply them in school and social life. Also, to translate them into educational situations that activate the mind of the learner and push him to more thinking; this corresponds to the beliefs of (Wahba, 2001, p.36) and (Wheatly et al., 2005).

Since the end of the 1980s, there has been a considerable interest in experimenting many nontraditional methods and strategies in both teaching and learning processes. One of these methods is the structural philosophy, which derives a variety of instructional models that are diverse, useful, and valuable in the process of teaching and learning (Tobin \& Tippins, 2003, p.6). 
The structural method asserts that the process of knowledge acquisition is considered an active and continuous process occurs through the modification of individual cognitive systems or structures (Appleton, 2007, p.309).

In his most basic description, Ubayd (2012, p.16) emphasizes that structural method is "to build the learner's knowledge through the direct interaction with the learning material, then to relate it to the learner's previous experiences and information. In addition to make changes on the basis of new meanings to produce new knowledge that the learner develops and supports through dialogues and group discussions with teachers and educated peers."

Therefore, the use of structural theory in teaching requires the teacher to know how each student builds his own knowledge, then each student can be helped to acquire new experience; this necessarily requires the teacher to ask the student some questions to clarify whether he has previous experience and he needs to deepen and not to deal with concepts in a superficial way. Also, the teacher needs to interact with each pupil separately to see how each of them builds knowledge. The use of the theory also requires the trend of the interpretation of the correct concepts and avoid the misinterpretations. In addition to the reliance on real experiences related to the scientific phenomena and events as a process of generating knowledge.

Many studies have found that dealing with the structural theory as a way of teaching promotes mental capacity development, and helps students to re-think of what they have learned. It also motivates students to learn and develop the skills of science processes, and helps students to give explanations and solutions. (Roger, et al., 2006, p.1-2) (Heron, L1, 2007, p.1564). The most famous models, based on the structural theory is:

\section{Bybee Model}

A model developed by the contemporary educational scientist, Roger Bybee, to teach science. It is primarily based on the structural theory and aims to build the student's own knowledge through the inquiry process that leads to learning. Roger Bybee, through the Biological Science Teaching Project, developed a structural learning model called Five Es because each phase in this model begins with an E (hence called the Bybee model (Ronis, 2014).

The Bybee model consists of five stages:

\subsection{Engagement Stage}

In most cases, there is a need to the preparation process in the beginning. At this stage, the teacher identifies the current understanding of the students, thrills them and draws their attention and stimulates their motivation, to engage them in thinking about the subject raised in the lesson. This stage includes: the distribution of students in groups via the activities to be conducted; so that each group consists of two or more individuals. The students identify the activities; they are encouraged to participate in. These activities are represented in questions about the natural world, the representation of a problematic situation or the presentation of events that involve surprise and astonishment or the introduction of a dangerous event, and the turning to problems of human adaptation to the environment (Szesge, 2011).

\subsection{Exploration Stage}

At this stage, students explore the concept or the skill or the behavior associated with the lesson being prepared by using their experiences. At the exploration stage, students have the opportunity to deal with the phenomenon and the materials available; so that the students deal with direct experiences that raise open-ended questions might be difficult to answer, through the students' individual or group activities. Students search for answers to questions that arise in their minds, as well as discover relevant concepts or principles through research, exploration, or group discussion, whereby the concepts and principles discovered are not known to them in advance. During the learning process, the teacher plays the role of encouragement and guidance to the students; so that they can carry out the required activities.

The purpose of this stage is to give students a state of shared experiences, that help them to feel the concept or the skill or the behavior. Here the students receive little explanation and clarification and a bit of vocabulary; because they will define the problem or phenomenon by using their words and their own style. Thus, the surveys carried out by the students lead the learning process through study and exploration. (Machnaz, 2011, p.1-19) (Michael, 2012, p. 1-2)

\subsection{Explanation Stage}

At this stage, the concept, skill, behavior or definition of terms is explained after the students have explored that concept, skill or behavior. At this stage, the teacher allows each group to present the information they have gathered through their exploratory experiences; the teacher helps them to logically arrange these information (Kathy, 2014, 


\section{p.1-9).}

\subsection{Elaboration Stage}

At this stage, students expand the concepts they have learned; whereby they establish relationships, then they link these concepts to the other relevant concepts and apply their understanding in their surroundings. Students apply the concepts and skills in new but similar situations, with using terms and definitions and thinking of the information and available evidences through exploring new situations. At this stage, the approach offers opportunities for students to apply what they have learned in exceptional situations. Furthermore, the lessons provide related ideas, that students explore and interpret using previous information and experiences. By interacting with each other in the group, students can build a deeper understanding of concepts, improve their skills by learning from other students and give students enough time to apply what they have learned; through enriching examples or providing the students with additional expertise to raise other survey skills (Miami Museum of Science, 2011, p.1-4).

\subsection{Evaluation Stage}

At this stage, the solutions and ideas concluded are assessed. The assessment process shall be continuous and not limited to the end of the semester or the unit. It is possible to do the assessment at each stage of the form throughout the teaching process. The assessment process is done for the previously lessons before starting the new lesson; it is called the pre-assessment. All the important concepts and skills and processes included in the lesson are assessed using the various assessment methods like standardized tests and notes lists and interviews with students; which helps them to judge what has been reached and see how well they can benefit from solutions (Anthony, 2011).

Highlighting what has been achieved enriches the understanding of all participants in the learning process; it can be a starting point for further enrichment of the learning process of students. Evidences or observations of learning may guide the teacher in the future planning of the lesson and may indicate the need for change and modification in direction. These evidences or observations of learning is valuable in the communication process between students, teachers, parents and managers.

After the previous presentation of the stages of the Bybee model and its educational importance, it is noted that the stages are integrated among them; where each stage leads to a specific function in preparation for the next stage. These previous steps in this model include a balance between the educational activities of the students and the information provided for them by the teacher related to these activities and facilitates the development of concepts. The steps of this model help the students build their concepts through their direct experiences, thus making them clearer if they are memorized (Mark \& Methuen, 2009, p.42).

The Bybee model offers the teaching process as a method of study; in which the learner turns from the part to the whole. This corresponds to the nature of learning that is based on the inductive method (Michael \& Howard, 1995, p.303). In learning new concepts, the learner, in the exploration stage, gather information and classify them; while in the concept presentation stage, the student helps the teacher to conclude the new concept of the information he has collected. In the expansion stage, the students expand the concepts they have learned; therefore, the new concept is used in new situations. This is compatible with the geography subject -the study sample- that the researcher selected to apply the Bybee model to. The selected educational unit bears the title of contemporary environmental problems and includes problems of the atmosphere (bio, air, water) and the problems of food and energy in the Arab world.

Which is perfectly consistent with the purpose of the structural model Bibi, whose steps have been explained previously. Geography is a fertile area for thinking of all kinds, from observing and collecting information and organizing it and connecting places with ideas and theories to different types of thinking (inductive, creative, analytical, critical and exploratory) To change ideas and analyze them.

\section{Problem-Solving}

Life in modern societies requires that the individual shall have the ability to make decisions that enable him to adapt and live with the demands of life. Decision-making in life situations has an essential role in creating good feelings for oneself on a continuous basis; which has a positive impact on living with life and encounter its problems.

Paul and Patricia (2006) point out to the importance of developing the learners' skills in solving life problems and communicating with others and helping them acquire confidence in their ability to successfully deal with life variables.

Whereas Janey sees that solving the problem is a type of learning within a hierarchical structure of eight types, in which the solution of the problem is the finest of the eight types of learning. John Deu believes that the problem is a 
state of confusion, questioning and hesitation which requires research or work to find out the facts that help reaching the solution (Qatami, 2000).

Guilford expressed the concept of problem-solving through his model of mental construction, to solve the broader and wider problems of creative thinking; although both of them contribute to reach a successful end by solving the problem; It is not possible to reach problem solutions without steps or innovative intellectual activities in one way or another. Guilford also asserts that problem-solving may involve all kinds of mental processes; whereas creative thinking is limited to some of these processes. Both problem-solving and creative thinking may include the information content for mental constructs (Jarwan, 2009).

Sternberg (2004) argues that problem-solving depends on conscious observation, experimentation, gathering information and assessment at the same time; which are the same steps as scientific thinking. Lamp (2001) defines problem-solving as a teaching strategy, in which the learner plays a positive role in order to overcome the difficulty that prevents him from achieving the desired goal. Also. Bransford and Barry (2003) see that problem-solving is: a set of operations performed by the individual using information and skills discovered to control the uncommon new situation that leads to the solution.

\subsection{Theories That Explained Problem-Solving}

\subsubsection{Behavioral Theory}

The owners of this school view the problem as a situation that can be subject to learning. This situation can be divided into a set of parts and elements, in which the learner walks step by step, determining each step as a criterion for success (Jarwan, 2008).

\subsubsection{Knowledge Theory}

The owners of this school believe that the problem represents a situation that poses a challenge on the cognitive abilities possessed by the individual, and interacts with him and evokes his previous experiences. In addition to that, problem-solving helps the individual to improve his/ her mental treatment of the situation; so that he can access new experience, which in turn represents a solution to the problem (Perez, 2006).

\subsection{Such Problems Are Classified into Three Types}

3.2.1 System problems: they reflect the weakness of information systems and the existence of gaps in work procedures and conditions and poor-quality control.

3.2.2 Humanitarian problems: such as weak sense of belonging, lack of motivation and weak cooperation, coordination and discipline.

3.2.3 Economic problems: these are related to increasing the level of expenditure and costs, weak liquidity ratios and poor resources (Flood \& Robert, 2005)

\subsection{Hayani and Walts Categorise Problems to Two Types}

3.3.1 Problem-solving as a "problem of assessment.": This type includes closed or systematic problems; so that students learn scientific skills and concepts in traditional ways and then test them by solving a problem in order to measure their achievement of scientific concepts.

3.3.2 Problem-solving as a "problem of learning": This type engages students in the solution of new problems they have never experienced in any way; to lead them to a scientific research, in which they learn new scientific concepts and acquire skills. This kind indicates that the problem was used for the purpose of learning and not for assessment.

We note that there is a difference in views concerning the explanation and classification of the problems, their kinds and ways of solving. Whether this difference is existed or not, there is an agreement that the problem is a state of tension and anxiety needs to be reduced using the stock of knowledge and experience and appropriate methods that lead to solving these problems. It is possible to train on how to solve the problem that may face the student's studies; therefore, the researcher worked hard in linking between what steps included in the Bybee model and found that these steps are consistent with the mechanism of mental and practical steps of the learners in the skill of problem-solving.

Hence the idea of the current study arises to reveal the effectiveness of teaching an educational unit using the learning strategy of the Bybee model in the development of the skills of problem-solving and academic achievement in the geography subject of the ninth grade students in Jordan. 


\section{Previous Studies}

This section deals with the Arabic and foreign studies related to the current study variables; learning using the Bybee model, problem-solving and achievement.

Al-Jubouri (2014) conducted a study aimed at identifying the effect of the method of problem-solving in the second-grade students' achievement in the Islamic subject. The experimental design of the two equal groups was used; which includes a control group was taught according to the usual method and an experimental group which was taught according to the problem-solving method. The research sample consisted of (51) students have been chosen randomly. The results showed that there was a statistically significant difference at the level of (0.05) between the academic achievement average of the students of the experimental group who studied according to the method of problem-solving, and the students of the control group who studied in the usual way in the collection and in favor of the experimental group.

In the Snyder's study (2013) which aimed at knowing the effectiveness of two structural models in maintaining the correct scientific concepts in the chemistry subjects at university. The results of the study showed a clear improvement in alternative concepts and perception of concepts in general.

The purpose of the study prepared by Elwan was to identify the relationship between information processing and the ability to solve problems in secondary school students. The study sample consisted of (270) male and female students. The researcher used the information processing scale and the ability to solve problems scale. The results of the study showed significant differences in the domains of the ability to solve problems scale according to the variable level of achievement.

In the study of Abdul Razek Hammam (2008), which aimed at identify the impact of using the 5Es learning course (the Bybee model) through computer in concluding some scientific concepts and scientific thinking and the impact of the trend towards science among students in the third grade in the Kingdom of Saudi Arabia. The results showed the impact of the E5s learning course in increasing the conclusion of some scientific concepts and the development of scientific thinking and the trend towards science.

Nawal Khalil (2007) conducted a study aimed at identifying the effect of using the structural model "Bybee" in developing awareness of the environmental risks for the first- grade students in science. The results showed that the effect of the model in increasing the educational achievement and developing awareness of the environmental risks.

Aliywa (2006) conducted a study aimed at determining the impact of using the structural model for learning, solving creative problems in the awareness beyond knowledge in reading the scientific texts and the ability to solve the problems of students in the primary schools in light of their cognitive style. The results showed significant differences in favor of the students who studied according to the problem-solving model.

In reviewing the previous studies, the researcher notes the effectiveness of the Bybee model in the development of thinking and awareness skills and the trend of the courses in which this model was applied, as well as the importance of associating the contents of thinking such as critical thinking with problem-solving skills and their relationship to academic achievement. The semi-experimental approach based on the experimental and control groups was adopted in most studies, including the Jubouri studies (2014). This study agrees with the current study in the use of the semi-experimental method. Furthermore, the secondary school has received the largest share of previous researches and studies. The current study is characterized by the study of the effectiveness of teaching an educational unit using the learning strategy of the Bybee model for the development of problem-solving skills and academic achievement in geography subject, in terms of the sample, society, research and variables.

\section{The Problem of Study}

The researcher seeks the reality of teaching the social studies in general and geography in particular through the field follow-up of trainees - within a practical education program for undergraduate students in both public and private schools. The researcher also considers the strong emphasis on the cognitive aspect as a single major goal of practical and scientific education within the classroom practices of teachers, which the researcher also touched and coexist with through his service in the field of teaching before joining the university teaching; this deprives the students of the opportunity to train on the development of the thinking processes skills and the ability to solve the problems in life situations, which leads to further conservation and memorization, without providing or enabling the skills to the students to think about relevant issues to subjects or even these -problems- associated with the process their daily and practical lives to learn how to understand and address them according to a clear and scientific vision. 
The acquisition of different thinking skills by students is considered one of the most important success factors in learning subjects and controlling their concluded ideas, concepts, indications. Therefore, the weakness of these materials reduces the academic achievement in quantity and quality, as well as the ability to form higher mental abilities; this may lead to the failure of the school life, especially in the upper stage where the student depends in his learning of the subjects on thinking, criticism and analysis rather than adoption and memorization and conservation (Titi, 2013; Tnawi, 2013). For the curricula of social studies, especially the geography book, which is taught by the researcher in a decade, we notice the absence of the enhancement of the skills of thinking, reflection, analysis and realization of the mind of the student because of the rigidity of teaching methods and the lack of focus on the learner as a center and a base for the learning process; as noted by the researcher while teaching this course, Geography, in previous years.

The researcher believes that studying geography through the Bybee model helps the learner to acquire many of the mental skills that enable him to solve problems. Using the Bybee model satisfies the natural desire to generate knowledge, reflection and questioning. It aims at helping students to build their own knowledge by using what they have to build new knowledge by training them at various stages, including many skills: Engagement, Exploration, Explanation, Elaboration, Evaluation (Kathy Ullich, 2014, p.1-4), (Najdi et al., 2005, p. 420). Thus, the current study was conducted to investigate the effectiveness of teaching an educational unit using the learning strategy of the Bybee model in the development of problem-solving skills and the academic achievement in the geography of 9th graders in Jordan.

\section{The Current Study Sought to Test the Following Hypotheses}

6.1 There are no statistically significant differences at the level of significance $(\alpha=0.05)$ between the control and the experimental groups in the development of the academic achievement of the geography subject due to the teaching strategy (the experimental group: The Bybee model and the control group: the usual method)

6.2 There are no statistically significant differences at the level of $(\alpha=0.05)$ between the control and experimental groups in the development of problem-solving skills due to the teaching strategy (experimental group: the Bybee model and control group: the usual method).

\section{Importance of the Study}

The importance of the current study can be summarized as follows:

- The results of the study introduce the teachers to the method of teaching in accordance with the Bybee model; which improves the students' ability in solving problems and thus improves the results of academic achievement.

- The results of the study help planners and developers of the social studies curricula in general and the geography curriculum in particular in taking into account the nature of the learner's thinking and in providing activities that suit the learning model "Bybee" in the preparation of the geography curricula.

- The results of the study constitute a starting point for researchers and learners to benefit from the tools of the current study and its results and recommendations in future studies, especially in light of the local studies dealing with the curricula of social studies and teaching models.

\section{Purposes of the Current Study}

- To determine the efficiency of the Bybee model in stimulating the learner's abilities and interacting with the classroom environment.

- To present a procedural model of how to use the Bybee model to develop problem-solving skills and academic achievement in geography in the ninth graders in Jordan.

- To provide teachers with a modern skill of the teaching skills and its methods, in order to develop the students' problem-solving skills.

- To determine the impact of using the strategy of Bybee model in the cognitive achievement in the ninth graders to develop the problem-solving skills and the academic achievement. 


\section{Conventional and Procedural Definitions}

Effectiveness: The global dictionary $(2011$, p. 3) defines effectiveness as "the effect that a program or a strategy have after its objectives have been achieved; as an independent variable that affects the variable or dependent variables." It is also known as the ability to influence, achieve goals, and achieve the desired results (Al-Laqani, Jamal, 2009, p. 49).

For the purposes of the current study, the "effectiveness" is defined as the effect of using the learning strategy, the Bybee model, in developing the ability to solve problems and the academic achievement in the history subject for the tenth graders.

\section{The learning model "Bybee":}

The model consists of five teaching steps used by the teacher. It aims at building the learner's scientific knowledge himself through the survey process that leads to learning according to the perspectives of the owners of the structural theory, and to the development of many concepts and scientific skills. This model relies on several stages (Wanda, 2005, p.1-4), (Zeitoun, 2013, p. 221-223) (Fahmi, 2012, p. 120-121) which are:

The Engagement stage, the Exploration stage, the Explanation stage, the Elaboration stage, the Evaluation stage.

Achievement: Obaidat and Abu Al-Sameed (2006, p. 14) define it as "the degree of acquisition achieved by the student, or the level of success achieved or reached in a given subject or field of education or training." The researcher defines the process of achievement as the acquired amount and what the ninth-grade students learn from knowledge and information about the geography content. Achievement is measured using the attainment test prepared for the purposes of the current study.

Problem - solving: It is defined as the ability of the individual to employ the information and skills he has acquired in encountering ambiguous situations. It involves complex processes of conversion, processing, organization, analysis, synthesis, and evaluation of the information in the situation and its interaction with previous experiences and knowledge, which constitutes the content of the memory to reach the solution and evaluate it (Alwan, 2009). Conceptually, it is defined as the range of processes, skills, ideas, measures, methods and strategies used by the learner to reach a complex or unusual solution (Aliwa, 2006). From the procedural aspect, the students' scores were measured according to the scale of problem-solving.

\section{The Limits of the Study}

- The study was limited to the ninth-grade students at the Mohammed Al-Shoraiqi Secondary School of the Ministry of Education, in the capital Amman, in the second semester of the academic year 2017/2018; Which may not allow the dissemination of the results of this study outside the sample.

- The content of education (educational material) was limited to the unit of "contemporary environmental problems" of the geography course for the ninth grade.

\section{The Study Limitations}

The results of this study can be determined and disseminated in the light of the following limitations:

- In terms of the sample: the study included an intentional sample of the study community; it was particularly represented in Mohammed Al-Shoraiqi Secondary School from the Directorate of Education in the capital Amman.

- In terms of the study tools: The results of this study are determined by the extent of the availability of its tools; which are: the cognitive attainment test and the scale of the ability to solve problems.

\section{Methodology of the Study}

The study followed the semi-experimental approach because it fits the study objectives.

\subsection{The Study Samples}

The study sample consists from (60) students of the ninth grade; table (1) shows the distribution of the sample according to the study approach, at Mohammed Al-Shoraqi Secondary School of the Directorate of Education in the capital Amman, in the second semester of the academic year 2017/2018. This school was intentionally chosen in the 
light of the following reasons: The nearness of the school from the workplace of the researcher, which facilitates the follow-up of the application of the study and the cooperation of the school administration with the researcher and allow him to apply the study. In addition to the presence of an experienced geography teacher for the ninth grade and ready to apply the study.

Table 1. Distribution of the Sample According to the Study Approach

\begin{tabular}{lccc}
\hline \multicolumn{1}{c}{ Group } & Pre-test & Process & Post-test \\
\hline Experimental (30) students & Attainment & $\mathrm{X}$ & Attainment \\
& Problem-solving scale & & Problem-solving scale \\
Control (30) students & Attainment & - & Attainment \\
& Problem-solving scale & & Problem-solving scale \\
\hline
\end{tabular}

\section{Procedures of the Study}

\subsection{Determining the Scientific Material:}

The scientific material to be taught during the period of the experiment is determined according to the vocabulary of the syllabus and its chronology in the geography book of the ninth graders in Jordan. The fourth module of the book entitled "Contemporary Environmental Problems" was selected. It includes problems of the atmosphere (bio, air, water) and food and energy problems in the Arab world.

\subsection{Formulating the Behavioral Objectives}

Behavioral objectives are defined as expressions that provide a comprehensive description of what a learner expects to show after teaching and learning process in a specific time period (Al-heelah, 1999, 115). Thus, the behavioral objectives of the geography content of the ninth graders were formulated and their levels were determined in the light of Bloom's classification of the cognitive field (recall, comprehension, application, analysis). These objectives were presented to the experienced and competent people, to ascertain their coverage of the content and the correctness of its formulation. The behavioral objectives that obtained (80\%) and more of the expert's opinions have been adopted as a criterion for the truthfulness of the analysis and their observations and suggestions. The behavioral objectives finally reached (100) behavioral objectives, (30) of which are recall, (20) comprehension, (40) Application, and (10) analysis.

\subsection{Preparing the Teaching Plans}

Teaching is a fine art work and is considered one of the most complex human occupations. It requires planning in terms of its objectives and methods (Al-Amin and others, 1994, p. 35). The teaching plans were prepared according to the learning strategy of the Bybee model, in the light of the principles and stages that were explained in the theoretical framework on five stages according to a sequence that suits the selected model. The lessons were planned according to these stages for ten teaching lessons for the experimental group. In order to verify the structure of teaching strategies, they were presented to five arbitrators specialized in the curricula and methods of teaching social studies; These arbitrators come from faculty members in Jordanian universities and other universities and geography teachers who hold a master's degree in the curricula and methods of teaching social studies. They were asked to give an opinion on the study plans that were built in terms of the language of the lessons' output and clarity, whether they are appropriate to apply to the ninth grade, the scientific accuracy in the formulation of activities and lessons, the accuracy of the evaluation and its clarity and the compatibility of the planning stages. In light of the arbitrators' observations, the proposed amendments were made to the program; thus, verifying the credibility and validity of the content of the Bybee model-based teaching strategies.

13.4 Choosing the school intentionally and identifying the sections selected in the study and dividing them (randomly) into two groups: experimental and control.

13.5 Applying the study tools (the cognitive attainment test, the ability to solve problems scale) to a sample outside the study community; to extract the difficulty and distinction treatments.

13.6 Applying the pre-study tools, previously mentioned, to the study sample.

13.7 Starting by teaching the learning unit according to the Bybee model for two lessons per week by the teacher; the treatment took ten teaching lessons.

13.8 Applying the post-study tools (the cognitive attainment test, the ability to solve problems scale) to the study 
sample.

13.9 Entering the data into the computer and processing them using the Statistical Package for Social Sciences (SPSS); thus, analyzing the results and elaborate them.

\section{Statistical Methods Used}

To answer the study questions and test the validity of their hypotheses, the data were analyzed to calculate the means and standard deviations, the significance of the differences between the mean scores of the experimental and control groups, and perform the $t$ test on the differences between the performance of the study sample of the pre-cognitive attainment test and the post one.

\section{Study Tools}

\subsection{First- the Attainment Test}

For the purpose of conducting this test, a specification table was prepared in light of the behavioral objectives, the weight of each chapter, and the value of each class and each level for the purpose of recall, understanding, analyzing, applying, synthesis and evaluating by preparing the behavioral goals. The number of the attainment test paragraphs is (30) paragraphs; suitable for the content of the teaching material. Table (2) shows the table of specifications for the content of the teaching material.

Table 2. Specifications of the Content of the Teaching Unit (Arabic Problems and Issues)

\begin{tabular}{|c|c|c|c|c|c|c|c|c|c|}
\hline \multirow{2}{*}{ 志 } & \multirow{2}{*}{$\begin{array}{r}\text { Ratio values } \\
\text { and No. of } \\
\text { questions }\end{array}$} & \multicolumn{6}{|c|}{ Teaching objectives } & \multirow{2}{*}{$\begin{array}{r}\text { Total No. } \\
\text { of } \\
\text { questions }\end{array}$} & \multirow{2}{*}{$\begin{array}{l}\text { Ratio } \\
\text { value }\end{array}$} \\
\hline & & Recall & Understanding & Application & Analysis & Synthesis & Evaluation & & \\
\hline \multirow{2}{*}{ 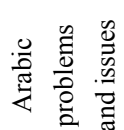 } & Ratio value & $6.7 \%$ & $10 \%$ & $20 \%$ & $23.3 \%$ & $20 \%$ & $20 \%$ & 30 & $100 \%$ \\
\hline & $\begin{array}{c}\text { No. of } \\
\text { questions }\end{array}$ & 2 & 3 & 6 & 7 & 6 & 6 & & \\
\hline
\end{tabular}

In the light of the table above, 30 behavioral objectives were selected, and then 30 test paragraphs were formulated; of multiple-choice types with four alternatives for the first four levels of Bloom's classification of the cognitive field. After the completion of the formulation of the paragraphs of the attainment test, the researcher has done the following:

\subsubsection{Validation of the Test}

The test is valid when it measures what is meant by its measurement, that is, it measures the function to which the test is assigned to measure (Roussans, 1991, p. 88). In order to verify the apparent validity and content of the test, the test paragraphs were presented to the experienced and competent persons. The item was considered valid if the agreement reached $80 \%$ or more of the experts; in light of their observations and opinions, the necessary amendments were made to the test paragraphs.

\subsubsection{The Exploration Experience}

In order to determine the clarity of the test paragraphs, their difficulty, the strength of their distinction and the time taken for the test, the test was applied to the ninth-grade students who were - from outside the sample of the study. In light of the students' queries during the application, it was clear that the test paragraphs were difficult and unclear. The time taken to answer the question was 50 minutes; it is the right time for the test. Then the answers were corrected by giving one score for the correct answer and zero for the wrong or abandoned one.

\subsubsection{Analysis of the Test Paragraphs}

The analysis of the test paragraphs means finding the coefficient of difficulty and the distinction of the paragraphs and determining the effectiveness of the alternatives to judge the validity of the paragraph (Rousan, 1991, p.80).

a- The coefficient of difficulty: 
The difficulty of the paragraphs is defined as: (the percentage of students who answered the question wrongly) (Oadeh, 2003, p.73). The coefficient of difficulty for each paragraph was calculated using the difficulty coefficient equation which ranged from 0.38 to 0.84 . Bloom considers that the coefficient of difficulty is acceptable if its value ranges from $20 \%$ to $80 \%$. (Bloom, 1993, p.107).

b- The Distinction of the paragraphs:

This means the ability to distinguish between high and low- level graders in the class being measured (Oadeh, 2003: 126). The distinction of the paragraphs was calculated for each test paragraph; it ranged from 0.28 to 0.50 . The paragraph is considered good if its distinction level is $20 \%$ and above.

c- The effectiveness of alternatives:

The wrong alternative is considered effective when it attracts a number of students in the lower group than the number of students in the higher group who are attracted by that alternative (al-Baghdadi, 1991, p.229). After examining the incorrect effectiveness of multiple-choice paragraphs, the number of students who were attracted to the wrong alternative in the lower level is bigger than them in the higher level; so, all the alternatives were considered effective.

d- The stability of the test:

Here, we mean the accuracy or consistency of the scale. (Abu Allam, 1999, p.152). The retesting method was used to calculate the coefficient of stability; it reached (0.89); a good stability coefficient. Tests are acceptable if the coefficient of stability is 0.67 and above (Grandlund, 2001, p.125)

e- The final formula of the test:

In the light of the previous procedures of validity, stability, finding the coefficient of difficulty and the distinction of the paragraphs, and the effectiveness of alternatives, the attainment test is ready to be applied and in its final form.

\subsection{The Problem-Solving Ability Scale}

To achieve the purpose of this study, a problem-solving ability scale was designed to measure the ability of ninth graders to solve problems before and after the experimental treatment.

To prepare the problem-solving ability scale, it was referred to the previous literature on problem-solving ability, such as the Alwan study (2009), the Aliuah study (2009); also, the tools included in some of them were used for the preparation of the problem-solving ability scale. The scale may be in its initial form, which consists of (43) paragraphs 12 paragraphs of which are negative paragraphs. The paragraphs were organized according to a three-step scale and were always given (3) degrees; sometimes they were given two degrees (2), and one degree rarely. The values (grades) were reversed in terms of the negative paragraphs.

The validity of the problem-solving ability scale:

To verify the validity of the problem-solving ability scale, it was presented to nine of the specialized arbitrators in psychology and curricula and teaching; these arbitrators are professors of Jordanian universities and other universities who hold a doctorate in the field of educational psychology, metrology and evaluation, and the curricula of social studies and teaching methods. They were asked to express their opinion on the following:

- The clarity of the paragraphs.

- The clarity of the language of the paragraphs.

- The extent of its relevance for the age group to which this study will be applied; which is represented by the ninth graders.

- The relevance of the paragraphs for the problem-solving ability scale that are limited by the current study.

In the light of the arbitrators' observations, the amendments were made by deleting certain paragraphs that were not appropriate for the age group to which the scale would be applied and deleting the duplicate paragraphs, as well as modifying the wording of some unclear ambiguous paragraphs. Thus, the final scale consisted of (30) paragraphs (12) of which are negative paragraphs.

The stability of the problem-solving ability scale:

To verify the stability of the problem-solving ability scale, the internal consistency coefficient was calculated using the Cronbach's alpha equation for estimating a sample of 38 students from the ninth grade of Mohammed al-Shoraqi secondary school. The internal consistency coefficient of the Problem-solving scale was $(0.83)$; this is a typical 
stability of this study. The criteria of the Cronbach's Alpha equation were used to judge the existence of the tool. These criteria vary according to the following gradation: $(0.80-1.00)$ typical stability and $(0.70-0.79)$ High stability, and (0.60-0.69) moderate stability, less than (0.60) low stability.

The correctness of the problem-solving ability scale:

The problem-solving ability scale consisted of (30) paragraphs were organized according to a three-step scale and were always given (3) degrees; sometimes they were given two degrees (2), and one degree rarely. The grades were reversed in terms of the negative paragraphs. Thus, the total score on the scale ranges between (30-90) degrees.

\section{The Variables of the Study}

The research design of this study includes the following variables.

First: the independent variable, which includes:

- $\quad$ The Bybee model

- The usual method

Second: the dependent variable, which includes:

- Attainment (achievement)

- Problem-solving ability

The results of the study and its discussion

Results related to equivalence between groups before the implementation of the study.

To demonstrate the equivalence between the study groups, the mean and standard deviations of the students' scores in the pre-cognitive attainment test were calculated, as shown in Table (3).

Table 3. The Means and Standard Deviations of the Students' Scores in the Pre-Cognitive Attainment Test Distributed as per the Teaching Strategy

\begin{tabular}{ccccc}
\hline & Teaching strategy & Number & Mean & $\begin{array}{c}\text { Standard } \\
\text { Deviation }\end{array}$ \\
\hline \multirow{2}{*}{ pre-cognitive } & The Bybee model & 30 & 14.00 & 3.091 \\
attainment test & The usual method & 30 & 12.72 & 4.334 \\
& Total & 60 & 12.45 & 3.254 \\
\hline
\end{tabular}

To examine the significance of the differences between the two groups, the T-test was used to detect the differences between the means of the two groups' performance in the pre-cognitive attainment test, as shown in Table (4).

Table 4. The T-test Results for the Differences between the Two Groups' Performance in the Pre-Cognitive Attainment Test

\begin{tabular}{lcccccc}
\hline Group & $\begin{array}{l}\text { No. of } \\
\text { students }\end{array}$ & Mean & $\begin{array}{l}\text { Standard } \\
\text { Deviation }\end{array}$ & (T) value & $\begin{array}{c}\text { Degree of } \\
\text { freedom }\end{array}$ & The significance \\
\hline Experimental & 30 & 15.04 & 0.856 & 59.765 & 1 & 0.05 \\
Control & 30 & 2.21 & 1.326 & & & \\
\hline
\end{tabular}

It is noted that there are no statistically significant differences in the pre-cognitive attainment test; which indicates the equivalence of the two study groups.

The results of the first hypothesis: There are no statistically significant differences at the level of significance $(\alpha=$ 0.05 ) between the control and experimental groups in the development of the achievement of the study of geography due to the teaching strategy (the experimental group used the Bybee model, the control group used the usual method).

This hypothesis was answered by finding the means and standard deviations of the grades of the study sample in the post-cognitive attainment test, as shown in Table (5). 
Table 5. The Means and Standard Deviations of the Grades of the Study Sample in the Post-Cognitive Attainment Test Distributed as per the Teaching Strategy

\begin{tabular}{lccc}
\hline \multicolumn{1}{c}{ Strategy } & Number & Mean & Standard Deviation \\
\hline The Bybee model & 30 & 13.14 & 4.32 \\
Control & 30 & 11.56 & 4.61 \\
\hline
\end{tabular}

To examine the significance of the differences between the two groups, the T-test was used to detect the differences between the means of the two groups' performance in the post-cognitive attainment test, as shown in Table (6).

Table 6. The T-test Results for the Two Groups' Performance in the Post-Cognitive Attainment Test According the Bybee Model

\begin{tabular}{lcccccc}
\hline \multicolumn{1}{c}{ Group } & $\begin{array}{c}\text { No. of } \\
\text { students }\end{array}$ & Mean & $\begin{array}{c}\text { Standard } \\
\text { Deviation }\end{array}$ & (T) value & $\begin{array}{c}\text { Degree of } \\
\text { freedom }\end{array}$ & The significance \\
\hline Experimental & 30 & 16.16 & 0.983 & 53.342 & 1 & 0.05 \\
Control & 30 & 2.17 & 1.756 & & & \\
\hline
\end{tabular}

The effectiveness of the Bybee model on the academic achievement:

Effectiveness means the ratio of students who achieved the intended level of objectives as well as their degrees in the attainment test (Kamp, 2001, 205). It also means the ability to influence and reach the goals and achieve the intended results (Laqany, al-jamal, 2009, 73). In order to measure the teaching method using the Bybee model, the Black's acquisition equation was used as shown in Table (7).

Table 7. The Means of the Experimental Group'S Degrees in the Pre-Cognitive and Post-Cognitive Attainment Test and the Black's Acquisition Equation's Ratio

\begin{tabular}{ccccc}
\hline $\begin{array}{c}\text { The mean of the } \\
\text { degrees in the } \\
\text { pre-cognitive test }\end{array}$ & $\begin{array}{c}\text { The mean of the } \\
\text { degrees in the } \\
\text { post-cognitive test }\end{array}$ & Maximum & $\begin{array}{c}\text { Acquisition } \\
\text { equation's ratio }\end{array}$ & Level of effectiveness \\
\hline 3.01 & 34.76 & 40 & 1.73 & Accepted \\
\hline
\end{tabular}

It is clear from the previous table that the ratio of the Black's acquisition equation is (1.73); this percentage falls within the range set by Black, which is from (1-2) This result shows that the use of the Bybee model in teaching the module of "contemporary environmental problems" has a high level of effectiveness.

\section{The impact size:}

The concept of the statistical significance of the results reflects the degree of confidence that the results or relationships attach, regardless of the size of the difference or correlation. While the concept of impact size focuses on difference or size (Rushdie Fam Mansur, 2007, 59). To determine the extent of the effect of using the Bybee model on the development of the academic achievement in the higher school students (ninth graders), the Ita $\left(\eta^{2}\right)$ and (d) values were obtained, as shown in Table (8).

Table 8. The $\eta^{2}$ and (d) Values and the Impact Size

\begin{tabular}{|c|c|c|c|c|}
\hline $\begin{array}{c}\text { The independent } \\
\text { variable }\end{array}$ & $\begin{array}{c}\text { The dependent } \\
\text { variable } \\
\end{array}$ & $\eta 2$ value & the (d) value & The impact size \\
\hline Using the Bybee model & $\begin{array}{l}\text { The academic } \\
\text { achievement }\end{array}$ & 0.98 & 19.4 & Big \\
\hline
\end{tabular}


It is clear from Table 8 that the impact size of using the Bybee model on the achievement of the experimental group is significant; since the value of " $d$ " is higher than 0.8 . The same result can be explained on the basis that 0.98 of the total variance of the dependent variable refers to the effect of the independent variable.

This can be explained by taking into consideration the teaching strategies of the principles and stages of learning; for example, the Bybee model, which provided a learning environment in harmony with the learners' thinking patterns. The stages of presenting the information according to the five stages of the learning model "Bybee" and the opportunity to deal with the available expertise make the material more interesting and exciting. In addition to the opportunity to learn and to listen to some sound effects related to the subject of the lesson open the room for consciousness and unconsciousness to involve in the process of education, as well as the employment of drawing and writing about the scientific information, that the student is exposed to are considered a principle states that searching for meanings is done through profiling; therefore enhancing the student's ability to understand concepts and represent them in the cognitive structures.

Sosa (2009) noted that the learning strategy of the Bybee model is conducive to learning in a better and unhindered way, by stimulating the sides of the brain so that the learner can solve problems, search and experiment to gain knowledge and acquire it.

This corresponds with the results of the study done by Abdul Karim (2010), which showed the superiority of the experimental group students on the students of the control group in terms of the academic achievement. The researcher attributed this to the design of computerized learning in the light of the theory of the learning model Bybee. Also, it corresponds with the study of Gozuyesil \& Dicki, (2014), which demonstrated the effectiveness of learning in the Bybee model in the development of academic achievement and the motivation of students to learn, especially in science, mathematics, language and social studies.

Results for the second hypothesis: There are no statistically significant differences at the level of significance $(\alpha=$ 0.05 ) between the control and experimental groups in the development of problem-solving ability due to the teaching strategy (the experimental group used the Bybee model and the control group used the usual method).

This hypothesis was answered by finding the means and standard deviations of the study sample grades in the problem-solving skills test, as shown in Table 9. Also, the value of the T- test for the students, as shown in Table (10), as well as finding the mean of the experimental group grades in the pre-attainment test and the post-attainment test and the Blacks' acquisition equation ratio, as in Table (11). At last, finding the value of $\boldsymbol{\eta} \mathbf{2}$ and the corresponding $\mathrm{d}$ value and the impact size as in Table (12).

Table 9. The Means and Standard Deviations of the Study Sample Grades in the Problem-Solving Skills Test Distributed as per the Teaching Strategy

\begin{tabular}{lccc}
\hline \multicolumn{1}{c}{ Strategy } & Number & Mean & Standard Deviation \\
\hline The Bybee model & 30 & 33.19 & 3.89 \\
Control & 30 & 30.21 & 4.85 \\
\hline
\end{tabular}

Table 10. The Value of the T- test for the Students in the Problem-Solving Skills Test as per the Bybee Model

\begin{tabular}{lcccccc}
\hline Group & $\begin{array}{l}\text { No. of } \\
\text { students }\end{array}$ & Mean & $\begin{array}{l}\text { Standard } \\
\text { Deviation }\end{array}$ & (T) value & $\begin{array}{l}\text { Degree of } \\
\text { freedom }\end{array}$ & The significance \\
\hline Experimental & 30 & 16.34 & .747 & 63.125 & 1 & 0.05 \\
Control & 30 & 2.41 & 1.149 & & & \\
\hline
\end{tabular}

Table 11. The Mean of the Experimental Group Grades in the Pre-Attainment Test and the Post-Attainment Test and the Blacks' Acquisition Equation Ratio

\begin{tabular}{lllll}
\hline $\begin{array}{c}\text { The mean of the } \\
\text { degrees in the pre- } \\
\text { problem-solving test }\end{array}$ & $\begin{array}{c}\text { The mean of the degrees in } \\
\text { the post-problem-solving } \\
\text { test }\end{array}$ & Maximum & $\begin{array}{c}\text { Acquisition } \\
\text { equation's ratio }\end{array}$ & Level of effectiveness \\
\hline 3.37 & 24.48 & 30 & 1.49 & Accepted \\
\hline
\end{tabular}


Table 12. The Value of $\eta 2$ and the Corresponding $d$ Value and the Impact Size

\begin{tabular}{lllll}
\hline The independent variable & The dependent variable & $\mathbf{\eta} 2$ value & the (d) value & The impact size \\
\hline Using the Bybee model & The problem-solving test & 0.97 & 13.00 & Big
\end{tabular}

It is noted from the previous analysis that there are statistically significant differences between the mean scores of the two groups in the problem-solving skills tool due to the teaching strategy.

The researcher believes that the strategy of teaching, based on the Bybee model, included problem-solving skills strategies. Also, the activities of the strategy included the problem of the research. In almost every lesson, a problem was posed to students; often was a problem of contemporary intellectual views and related to the cognitive content of the lesson at the same time. Students are trained to connect the theoretical knowledge they received in the classroom with the practical reality surrounding them. The student, through his quest to solve the problem and to search for information, was able to build a sense of his own; thus, meaningful learning takes place, which is considered one of the principles of the Bybee model.

Some of the problems were posed in the lessons in the form of questions, according to the principle of promoting teaching and challenging and motivational learning, and discouraging fear and threat. These problems were also used to evaluate students' performance. The method of organizing the cognitive content in the strategy of the conceptual maps in organized steps and according to stages created an organized method for the student to deal with problems that might face him/ her; as per the principle of searching for meaning through profiling. Furthermore, creating an atmosphere of familiarity between students, providing a harmonious learning environment, and the principle that states that passion is a crucial factor in learning and profiling; also, allowing the opportunity to reflect on what has been learned, listening to sound effects, and displaying videos or images using the computer helped the students to solve the problems them might encounter. As well as the principle of consciousness and unconsciousness, which engaged in the learning process and the principle of the existence of two types of memory; spatial and invocational. In addition, assigning students to search for solutions to life-related problems and to search for causes and solutions to these problems from the principle that learning is an evolutionary and structural process enabled students to solve the problems they may encounter in terms of study and life. Therefore, this helped the application of this strategy thus improved students' ability to solve problems.

The researcher also believes that the strategy of the Bybee model, with its activities and exercises, exposed the learner to the situations related to their environment, as well as the development of motivation through interaction with peers, in addition to enabling learners to use their sensory, visual and kinetic talents. This increased their turnout to learn and increased their motivation; this may indicate the effectiveness of the learning theory "the Bybee" model. It can be because of a high motivation to learn, the lack of threat methods, the use of many teaching aids, direct feedback, ongoing evaluation, and encouraging factors for learning such as music, movement and scenery.

In the context of this interpretation, there is a lack of Arab and Foreign studies - within the limits of the researcher's knowledge - that addressed the impact of learning through using the Bybee model in the development of solving -problems ability. This study is unique in investigating the effectiveness of teaching an educational unit using the learning strategy, the "Bybee" model, in the development of problem -solving and academic achievement skills in the geography subject of ninth graders in Jordan. However, it is consistent with the results of the previous studies that addressed the impact of teaching according to the creative solving of problem or the relationship between information processing and the ability to solve problems such as the study of Aliwa (2006).

This result is also consistent with the result of the Jubouri study (2014), which showed a statistically significant difference at the level of $(0.05)$ between the average of the students of the experimental group who studied the method of problem-solving, and the students of the control group who studied in the usual way of academic achievement; the results were in favor of the experimental group.

\section{Conclusion}

1- Consideration the teaching strategies of the principles and stages of learning; for example, the Bybee model, which provided a learning environment in harmony with the learners' thinking patterns.

2- The researcher believes that the strategy of teaching, based on the Bybee model, included problem-solving skills strategies 
3- The researcher also believes that the strategy of the Bybee model, with its activities and exercises, exposed the learner to the situations related to their environment

\section{Recommendations}

In the light of the current research results, the researcher recommends the following:

1. Confirming the use of the Bybee model as a learning strategy by the geography teachers in the training programs held for teachers.

2. Adopting the topics and stages of the learning strategies when constructing or developing the curriculum because of their impact on the conceptual and cognitive content of the learner and the problem-solving ability.

3. Conducting empirical research and studies on this type of learning to prove its effectiveness, compared to other teaching methods and variables.

\section{Arabic References}

Abdul Karim, Munther. (2010). Instructional design according to the learning theory of the Bybee model and its impact on the achievement of intermediate second grade students in chemistry. Al-Fath Journal: Iraq, University, 14(44), 45-67.

Abdul Razzaq Swailam Hammam. (2008). The impact of the use the Efives learning cycle through the computer in the collection of some scientific concepts and scientific thinking and the trend towards science among eighth grade students in the middle of Saudi Arabia.

Abu Allam, Raja'. (1999). Introduction to educational research curricula. Kuwait: Al Falah Library for Publishing and Distribution.

Ahmed Hussein Al-lqani \& Ali Ahmed Al-jamal. (2009). Glossary of educational terms in curricula and teaching methods (2nd ed.). Cairo: Alam Alkotob.

Al- Titi, Muslim. (2013). The impact of a learning program using the "Bybee" in terms of learning motivation of students in the fifth grade in science. Studies in Education and Psychology: Saudi Arabia, 3(44), 11-39.

Albagdady, Mohammed Reda. (1991). Objectives and tests between theory and practice in curricula and teaching methods. "Alflah" library: Kuwait.

Alhela, Mohammed \& Tawfiq, Mar'i. (1999). General methods of teaching. Amman: Almaseera.

Aliwa, Raed. (2006). The impact of the use of two models of learning, creative problem solving in the awareness of knowledge beyond the reading of scientific texts, and the ability in solving problems in the students of the upper stage in the light of their knowledge. P.H.D proposal (unpublished), University of Jordan, Amman, Jordan.

Aljabori, Adnan. (2014). The effect of the method of solving problems in the achievement of students in the second grade intermediate in Islamic education subject. Journal of Research College of Basic Education: University of Mosul, 13(1), 149-172.

Al-Najdi, Ahmed et al. (2005). Recent Trends in Science Learning in the Light of International Standards and Development of Thinking and Structural Theory. Cairo: Dar "Al-Fikr Al-Arabi".

Alrousan, Saleem Salameh. (1991). Principles of measurement and evaluation and its educational and human applications. Cooperative Printing Presses Workers Association.

Altantawi, Efat. (2013). Effective teaching: its planning, skills, strategies, and evaluation. Amman: Al Masirah.

Alwan, Musab. (2009). Information processing and problem solving ability for secondary students. Unpublished MA, Islamic University, Gaza, Palestine.

Blom, benyamin et al. (1993). Assessment of student's cumulative and formative learning (translation: Mohamed Amin Mufti). Cairo: Alkottab Almasri.

Farouq Fahmy, Mona Abdel Sabour. (2012). The Systemic Approach in Facing Contemporary and Future Educational Challenges. Cairo: Dar Al Ma'arif.

Husam Mohammad Mazen. (2012). Scientific education, the dimensions of technological development, the scientific 
and cultural life skills required for the Arab citizen, future vision, the fateful association for scientific education, the scientific education journal, the sixth scientific conference, scientific education and the culture of society. Al'esma'elia, 2, 28-31.

Jordanian Ministry of Education. (2013). National Standards for Learning in Jordan, Amman. Teacher's Journal, 50, $15-23$.

Kamal Abdel Hamid Zeitoun (2013). Teaching models and skills. Cairo: Alam Alkotob.

Nawal Abdel Fattah Fahmy Khalil. (2007). The Effect of Using the Structural "Bybee" Model in Developing Environmental Risk Awareness among seventh Graders in Science, The Egyptian Association for Scientific Education. Journal of Scientific Education, 10, Third edition, September.

Obaid, William (2012). Constructivism, Psychological Concept and Educational Significance. Paper presented at the Structural Seminar and Systemic Approach in Learning and Education, Faculty of Education, Sohag.

Obeidat, Toukan \& Abu Samaid, Suhaila. (2005). Brain, learning and thinking. Amman: De Bono.

Oudeh, Ahmed. (2003). The basics of scientific research in education and humanities (research elements, concepts and statistical analysis of its data). Irbid: "Beidoun" Center.

Rushdy Fam Mansour. (2007). Effect volume of the complementary face of statistical significance. Egyptian Journal of Psychological Studies, VI(VII).

Sosa, David. (2009). Human brain and the phenomenon of learning (translation: Khalid Al-ameri). Cairo: Al Farouk.

Wahba, Murad. (2001). Creativity and Public Education. Cairo: National Center for Educational Research and Development.

Yacoub Hussein Nashwan. (2005). Scientific Thinking and Scientific Education. Amman: Jordan Al-Furqan for Publishing and Distribution.

\section{References}

Anthony, W. Lorsbach. (2011). The Learning cycle as a tool for planning Science Instruction. (N. d). Retrieved August 4, 2011 from http://www coeilstu.edu/ Scienced/Lorsbach/257lrey.html

Appleton, K. (2007). Analysis and Description of student's Learning During Science classes Using a constructivist Based Model. Journal of Research in Science Teaching, 34(3), 303-318. https://doi.org/10.1002/(SICI)1098-2736(199703)34:3\%3C303::AID-TEA6\%3E3.0.CO;2-W

Cozuyesil, E., \& Dicki, A. (2014). The Effect of Brain Based Learning on Academic Achievement: A Meta-analytical Study. Educational Sciences: Theory \& Practice, 14(2), 642-648. https://doi.org/10.12738/estp.2014.2.2103

Dictionary.com. (2011). Effectiveness, Define Effectiveness at Dictionary.com. Retrieved on 23/5/2016 from $\mathrm{http} / / /$ dictionary.reference.com/browse/effectiveness

Heron, I. (2007). Using constructivist Strategies in High School Science Classrooms to Cultivate Positive Attitudes toward science Diss. Abst. Inter., 58(5).

Kathy Ullrich. (2014). Constructivism and the five E's model science lesson. Retrieved from http://cte.Jhu.edu./teachacademy/Fellow/Ulrich/Webquest/MKwinde.x.html

Machanz, M. (2011). Applying Constructivist and Objectivist Learning theories in the Design of A web- Based course: Implications for practice. Educational technology \& society, 4(3).

Maimi Museum of science. (2014). The PH factor / Constructivism and the five E's. Retrieved from http://www.Miamisci.org/ph/pintro5e.html

Mark, E., \& Methuen, B. (2009). Effects of the Learning Cycle Upon Student and Classroom Teacher Performance. Journal of Research in science teaching, 28(1), 41-53. https://doi.org/10.1002/tea.3660280105

Michael, J. S. (2012). 5E's "Strategies for Teaching Science. Retrieved from http://www.mcpsk12md.us/curriculum/science/5estrategieshtm1

Paul, H., \& Patricia, W. (2009). Work shop on Environmental Life Skills \& teaching Methods. Teacher college of Education, Rustaq sultanate of oman, March 23. 
Roger, et al. (2006): A Constructivist Design and Learning Model: Time for a Graphic. Retrieved from http://searchERIC.org/ericdb/ed391831.htm1

Ronis, D. (2014). The Five Science Inquiry and Constructivist Model, (n.d). Retrieved August, from http://www.skylight.edu.com/neighbor/articles/artic032CFM

Snyder, E. (2013). Molecoular Structure and Properties: Teaching and Learning for Basic Understanding. Retrieved from http://www.Asysue.edu/chem/fipse/bsnyder-fultest.pdf

Szesge, Michael. (2011). 5"E's Strategies for Teaching Science. Retrieved October 1 from http://www.mcps.K12.md.us/curriculum/science/inter/5e.strategies.html

Tobin K., \& Tippins, D. (2003). Constructivism as Referent for Teaching and Learning. In Tob, K. in (Ed.), The Practice of constructivism in science Education. Washington.

Tumkaya S., Aybek, B., \& Aldag, H. (2009). An investigation of university students' critical thinking disposition and perceived problem solving skills. Eurasian Journal of Educational Research, 36(3), 57-74.

Wheatly, G. et al. (2005). Radical constructivism as a basis for mathematics reform. Paper presented at the annual meeting of the North American chapter of mathematics education.

Yasin, R., Halim \& Ishar, A. (2012). Effects of Problem-solving Strategies in the Teaching and Learning of Engineering Drawing Subject. Asian Social Science, 8(16), 56-72. https://doi.org/10.5539/ass.v8n16p65 